
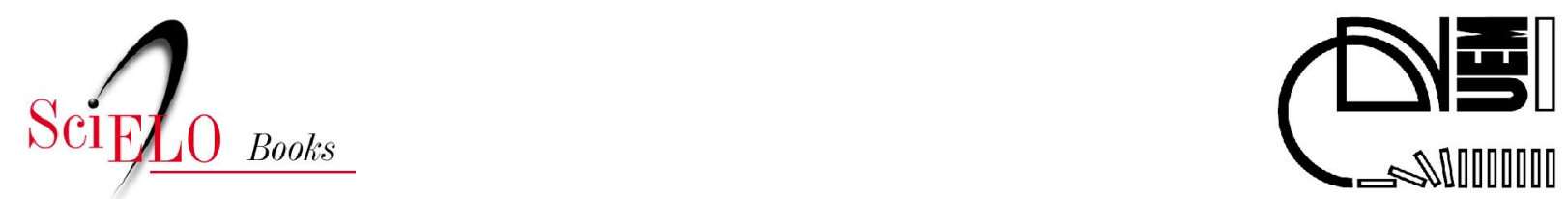

\title{
II. Fundamentos ambientais da colonização agrária no norte do Paraná
}

\author{
Paulo Astor Soethe (org.) \\ Daniel Martineschen (coord.) \\ Caio Heleno da Costa Pereira \\ Dionei Mathias \\ Elisete Antoniuk \\ Fernanda Boarin Boechat \\ Frederico Füllgraf \\ Natasha Pereira da Silva \\ Sibele Paulino \\ Sirlene Nair Neubauer \\ (transl.)
}

\section{SciELO Books / SciELO Livros / SciELO Libros}

SOETHE, PA., org. MARTINESCHEN, D., et al., transl. KOHLHEPP, G. Fundamentos ambientais da colonização agrária no norte do Paraná. In: Colonização agrária no Norte do Paraná: processos geoeconômicos e sociogeográficos de desenvolvimento de uma zona subtropical do Brasil sob a influência da plantação de café [online]. Maringá: Eduem, 2014, pp. 33-43. ISBN 978-85-7628-655-4. Available from SciELO Books $<$ http://books.scielo.org $>$.

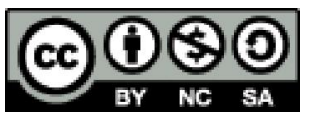

All the contents of this chapter, except where otherwise noted, is licensed under a Creative Commons Attribution-Non Commercial-ShareAlike 3.0 Unported.

Todo o conteúdo deste capítulo, exceto quando houver ressalva, é publicado sob a licença Creative Commons Atribuição Uso Não Comercial - Partilha nos Mesmos Termos 3.0 Não adaptada.

Todo el contenido de este capítulo, excepto donde se indique lo contrario, está bajo licencia de la licencia Creative Commons Reconocimento-NoComercial-CompartirIgual 3.0 Unported. 


\section{FUNDAMENTOS AMBIENTAIS DA COLONIZAÇÃO AGRÁRIA NO NORTE DO PARANÁ ${ }^{13}$}

\section{ESTRUTURA GEOLÓGICA E FORMAÇÕES DE SUPERFÍCIE}

A estruturação geológica do sul do Brasil revela, principalmente no Paraná, uma ordenação muito clara (Mapa 2): a leste, sob forma de degrau com $2.000 \mathrm{~m}$ de altitude, as dobras montanhosas cristalinas precipitam-se abruptamente no Atlântico. A oeste, outro degrau íngreme parte da Serra do Mar e desfralda-se em um planalto cristalino, com 900 a $1.000 \mathrm{~m}$ de altitude.

Em sentido oeste, sobre esse Planalto cristalino acumularam-se poderosas camadas paleozoicas e mesozoicas, que esculpiram notáveis degraus na paisagem, cujas faces estão direcionadas tanto para o leste, como o oeste (ALMEIDA, 1949). Em sentido noroeste, as camadas decaem suavemente em direção ao Rio Paraná, que pode ser compreendido como eixo sinclinal de uma enorme bacia sedimentar (LEHMANN, 1958, p. 54).

O segundo plateau interior - o planalto paleozoico - é constituído por arenitos, xistos argilosos e outros depósitos de origem devônica, carbônica e pérmica, formando um 'teto' a partir de $1.100 \mathrm{~m}$ na beirada do escalão de sedimentação, que a leste sobrepuja o planalto cristalino com $200 \mathrm{~m}$, e a oeste com $600 \mathrm{~m}^{14}$.

A partir dele prolonga-se um terceiro escalão de superfície com várias centenas de metros de elevação, constituído por arenitos mesozoicos, e que na jazida encontra-se erguida por poderosos bancos de rochas básicas eruptivas. Na aresta desses degraus (no Paraná, a Serra da Boa Esperança), os relevos alcançam $1.200 \mathrm{~m}$, enquanto que em sentido noroeste o planalto decai até 200-300 m em direção aos rios Paraná e Paranapanema.

As gigantescas fendas distendidas, que ocorrem em sentido noroeste-sudeste, sob forma de camadas de lava em derramamentos sucessivos, com seus 1,2 milhões de $\mathrm{km}^{2}$ no planalto mesozoico ${ }^{15}$ do sul e sudeste brasileiros, pertencem às maiores expressões vulcânicas da Terra (BAKER, 1923; BEURLEN, 1970).

As camadas de meláfiras ${ }^{16}$, diábases e basaltos do triássico superior, respectivamente do jurássico inferior ${ }^{17}$, formadoras das camadas de lava, alcançam extensões que vão de 50 a $600 \mathrm{~m}$. Elas se sobrepõem aos arenitos triássicos de Botucatu da série São Bento (ver nota 14), que em parte também apresentam finas incrustações de lava.

A disseminação de extrusões vulcânicas é de particular importância para o norte do Paraná, uma vez que seus produtos expostos aos agentes atmosféricos deteriorantes, como p.ex. os solos extremamente férteis de argila vermelha (terra roxa), tornaram a região um dos mais importantes centros de cultivo cafeeiro.

Em sentido noroeste, é possível reconhecer rochas básicas eruptivas sob formações de arenitos jurássicos e cretáceos, que em São Paulo (Arenito de Bauru) estão disseminados por extensas áreas, de modo que as camadas de lava estão expostas apenas de forma marginal (FRANÇA, 1956, p. 29ss.; ver Mapa 2).

Já no Paraná, numa extensão de aprox. 14.000 km², que vai até o rio Piquiri (Norte Novíssimo), apenas no noroeste do Estado encontramos arenitos eólicos do Cretáceo Superior, que em oposição aos

13 Tradução de Frederico Füllgraf.

Ver Maack (1953): Mapa geológico do Estado do Paraná 1:750 000.

15 No Paraná, visto de leste em sentido oeste, em geral chamado de Terceiro Planalto.

16 Pórfira ígnea escura contendo cristais de feldspato [N.T.]

17 Conforme as mais recentes pesquisas geo-cronológicas, a datação correta da série São Bento não seria triássico-jurássica e, sim, jurássico-cretácea (EL-KHATIB, 1969, v. 2, p. 100). 
Arenitos de Botucatu, toscos, apresentam uma granulação de fina até média; em geral, são chamados de Arenitos de Caiuá (MAACK, 1940 e 1947).

Com o depósito dos Arenitos de Caiuá, chegava ao fim nesta região o grande ciclo de sedimentação. Já na fase erosiva que se seguiu, as jazidas de basalto foram parcialmente liberadas. Sobre sua fronteira oriental de disseminação, o Arenito Caiuá, solto e avermelhado, apresenta volumes de 10 a $20 \mathrm{~m}$, que, porém, aumentam de 200 a $250 \mathrm{~m}$ em sentido oeste (EL-KHATIB, 1969, v. 2, p. 106). Enquanto no Norte Novo do Paraná é possível encontrar apenas algumas ilhas isoladas do Arenito Caiuá, situadas ao norte do principal divisor de águas entre os rios Tibagi e Pirapó, e desatadas pela ação da erosão, com volumes que vão de 20 a $70 \mathrm{~m}$, os rios tributários do Paraná no Norte Novíssimo provocaram incisões apenas parciais nas bases basálticas. Somente nos vales do Paranapanema e do Ivaí a superposição do Caiuá encontra-se estrugida em sentido oeste-noroeste, e a fronteira geológica entre Caiuá e camadas de lava [Trapp] apresenta-se descontinuada.

No Paraná, o escalão do planalto mesozoico estende-se desde Santa Catarina em sentido sul/ sudeste-norte/noroeste, e somente descreve uma curva quando o rio Alonzo desemboca no rio Ivaí. Os tributários respectivamente dos rios Paraná e Paranapanema, interrompidos por grande número de corredeiras e cascatas, como o Ivaí, Tibagi, Laranjinha e Cinzas, cortam esse escalão em vales de ruptura antecedentais (MAACK, 1968, p. 272).

O território objeto da presente pesquisa compreende um recorte do planalto mesozoico, entre o rio Tibagi, a leste, e o Piquiri, a sudoeste, como também uma pequena parcela desse mesmo planalto na perna do Ivaí (Mapa 2). Os rios Piquiri, Ivaí e Tibagi produziram cortes incisivos nas camadas mesozoicas, de modo a desmembrar o campo da observação em dois blocos: o do planalto de Campo Mourão (entre o Piquiri e o Ivaí) e o de Apucarana (entre Ivaí e Tibagi), por sua vez desmembrado pelo rio Pirapó, apresentando em seu setor norte um relevo apenas levemente ondulado (Mapa 3).

Enquanto nas bordas do escalão do Terceiro Planalto ainda predominam altitudes de $1.000 \mathrm{~m}$ ou mais, o bloco do planalto no setor norte decai para $300 \mathrm{~m}$ acima do nível do mar, na foz do Tibagi, e para $250 \mathrm{~m}$ acima do nível do mar na foz do Paranapanema, ao precipitar-se no rio Paraná.

O rio Paraná, que pouco antes de atingir Guaíra, a $15 \mathrm{~km}$ da foz do Piquiri, ainda possui uma largura de $4 \mathrm{~km}$, derrama-se nas Sete Quedas, por sua vez consideradas um dos maiores conjuntos de quedas d'água do mundo ${ }^{18}$, com um canhão de $50 \mathrm{~km}$ de comprimento, cujos paredões verticais de meláfiras distam apenas entre 60 a $80 \mathrm{~m}$ uns dos outros. Com nível médio de volume, o espelho d'água do rio situa-se a $120 \mathrm{~m}$ de altitude, aos pés das cachoeiras ${ }^{19}$.

A inclinação das camadas em sentido noroeste e a alternância de variados sedimentos resistentes e de intrusões intermediárias criam a oeste do Tibagi um relevo fortemente diferenciado. Rios consequentes e rios subsequentes menores recortam a superfície do planalto.

As divisoras d'água estendem-se sob forma de encostas rasas, fracamente arredondadas e estiradas entre os vales e ribeiras, e em parte apresentam - principalmente na área dos arenitos, ao norte do Ivaí e na região de Umuarama - expansões à semelhança de planaltos (Mapa 3).

Os territórios das divisoras d'água são fragmentados por grande número de pequenos rios afluentes do Piquiri, Ivaí, Pirapó e Tibagi em chapadas, morros e encostas de terreno estreitas, estendidas e planas. As encostas localizadas entre $400 \mathrm{~m}$ e $850 \mathrm{~m}$ de altitude apresentam condições de relevo e altitude ideais para a cafeicultura no Paraná. Contudo, os vales pequenos são evitados como calhas de absorção de ar frio.

Em casos de inclinação mais acentuada das encostas, manifesta-se rápida erosão dos arenitos, que nos sedimentos soltos do Caiuá em pouco tempo é capaz de sulcar precipícios com mais de 10m de profundidade, chamados voçorocas, provocando o arrasto do solo arenoso (KUROVSKI, 1962).

Tendo em vista a qualidade dos solos para o desenvolvimento do terreno agricultável, a diferenciação geológica do Norte do Paraná entre zona de rochas vulcânicas eruptivas, a leste, e arenitos eólicos, soltos, a oeste, é de suma importância. Uma vez encerrado o ciclo agrário pioneiro, e

18 O potencial hidráulico em nível médio de águas do rio Paraná foi estimado ali em 13,5 milhões de kW (MAACK 1968, p. 253) representando a mais importante fonte energética até agora conhecida e, do ponto de vista técnico, explorável com relativa facilidade. Em 1975, 150 km rio abaixo, iniciar-se-ão as obras da Hidrelétrica Itaipu, de grande porte, como projeto bilateral, brasileiro-paraguaio, cujo potencial instalado deverá alcançar 10,7 milhões de kW.

19 Como é sabido, com o fechamento das eclusas da Hidrelétrica de Itaipu, o conjunto das Sete Quedas foi submergido definitivamente em 1983. Como documento memorial, recomenda-se o filme Quarup Sete Quedas (1983). [N.T.] 
muito particularmente para estes meados da década de 1970, esta configuração pode ser confirmada como pré-requisito do planejamento regional da ocupação do território rural e das eventuais medidas de investimento de parte do próprio Estado.

\section{FATORES CLIMÁTICOS DE ORDENAMENTO ESPACIAL}

O clima da região pesquisada, como de resto o da Região Sul do Brasil, encontra-se sob a influência de três categorias de massas de ar, que determinam seu caráter de zona climática de transição. Nesta zona convergem massas de ar atlântico-tropicais e equatorial-continentais. Devido à influência constante, durante o ano todo, do vento Passat-sudeste ${ }^{20}$, as massas de ar atlânticas adquirem grande importância. Contudo, principalmente no período que vai de outubro a março, ar tropical quente-úmido desprendese da Bacia Amazônica e dirige-se ao sul, provocando fortes precipitações convectivas e determinando o curso da intempérie durante esse período.

Entre abril e setembro, devido à infiltração de massas de ar frio durante o avanço dos anticlones no Atlântico sul, arrefece a influência das massas atlânticas tropicais, que se manifestam na área pesquisada em sentido nordeste-leste, aqui devido ao encurvamento das correntes "passatistas" durante seu choque com as bordas orientais do continente. A intensidade alternada das correntes de ar frio, que costumam trazer consigo chuvas frontais e geadas, além da oscilação do curso tomado pelas frentes frias, são de particular importância para o Norte do Paraná (IBG, 1968; ver tb. Cap. VII, l).

As condições de temperatura, em particular a ocorrência de geadas, são de fundamental importância para a expansão e/ou retração da cafeicultura no Norte do Paraná. "A fronteira vegetal e agroclimática do trópico quente segue [...] em segmentos continentais da borda exterior dos trópicos, a fronteira de ocorrência de geadas" (WISSMANN, 1948, p. 87). Em oposição às zonas oceânicas, nesse setor, a fronteira das geadas encontra-se mais próxima da Linha do Equador, ou abaixo da fronteira de baixo calor da cafeicultura lucrativa, cuja temperatura média anual segundo Wissmann $\left(1948\right.$, p. 86) é de $18,3^{\circ} \mathrm{C}$. Em suas bordas a zona tropical de transição é caracterizada por algumas áreas com evasão desimpedida de massas de ar frio e, portanto, livre de geadas; já as bacias, vales e baixios, estão, sim, sujeitos ao efeito das geadas.

$\mathrm{Na}$ área pesquisada, a temperatura média anual oscila entre $19,5^{\circ} \mathrm{C}$ e $22^{\circ} \mathrm{C}$, isto é, para o cultivo do café, que ali ultrapassa o trópico, estas são temperaturas ideais (Mapa 4, estações 1 e 2). Com muita ênfase, na tabulação da temperatura média anual, transparece a transitoriedade em sentido norte-sul ${ }^{21}$. No extremo noroeste do Paraná, a isoterma anual de $22^{\circ} \mathrm{C}$ corta os vales do Paraná e Paranapanema. Enquanto que no Vale do Ivaí e na Bacia do Paraná a média anual de $20^{\circ} \mathrm{C}$ ainda se manifesta em profundidade, ao sul, a média nos pontos mais elevados do Planalto cai rapidamente abaixo de $18^{\circ} \mathrm{C}$.

A média mensal mais alta é atingida no Norte do Paraná no mês de janeiro e, dependendo da altitude, situa-se entre $23^{\circ} \mathrm{C}$ e aprox. $26^{\circ} \mathrm{C}$. As médias mensais mais baixas manifestam-se em junho e na zona da cafeicultura situam-se entre $16^{\circ} \mathrm{C}$ e $18^{\circ} \mathrm{C}$. Em zonas tropicais de fronteira, o andamento anual das temperaturas alcança valores característicos, entre $7^{\circ} \mathrm{C}$ e $10^{\circ} \mathrm{C}$, cuja amplitude diária nos meses de verão pode atingir em média $10^{\circ} \mathrm{C}$, mas que na estação invernal pode alcançar mais do que $20^{\circ} \mathrm{C}$.

Enquanto as mínimas absolutas em elevações favorecidas (p. ex. Londrina, com $610 \mathrm{~m}$ de altitude, cf. Figura 1,1) raras vezes caem abaixo do ponto de congelamento, em Apucarana $(870 \mathrm{~m})$ já foram medidos $-7^{\circ} \mathrm{C}$ e, devido à formação de um lago de massa de ar frio no Vale do Paraná, em Guaíra (265 m) foram registrados $-5^{\circ} \mathrm{C}$. As mínimas invernais médias situam-se entre $11^{\circ} \mathrm{C}$ e $13^{\circ} \mathrm{C}$.

20 O Passat (de passar, em português, ou passata, em italiano) é um vento forte e constante, que irrompe nos trópicos na longitude aproximada de $23,5^{\circ}$ e sopra ao redor de todo o globo terrestre [N.T.].

21 Indicadores climáticos em: Simões (1954 e 1956); CIBPU (1955 e 1958) e Maack (1968). 
As temperaturas máximas absolutas oscilam entre $37^{\circ} \mathrm{C}$ e $40^{\circ} \mathrm{C}$, sendo que em todos os meses as temperaturas do meio-dia poderão alcançar mais de $30^{\circ} \mathrm{C}$, e as máximas médias do mês mais frio (junhojulho) podem mesmo atingir de $22^{\circ} \mathrm{C}$ a $24^{\circ} \mathrm{C}$.

Apesar de que em todo o território dos Nortes Novo e Novíssimo do Paraná a média anual de temperatura situe-se acima do limite crítico de $18,3^{\circ} \mathrm{C}$, a ocorrência de geadas avança para zonas mais ao norte, e sua manifestação anual acaba impedindo a expansão de culturas tropicais suscetíveis às geadas, como o café, em direção ao sul.

Devido ao número reduzido de estações meteorológicas, a representação cartográfica da ocorrência de geadas apresenta dificuldades. O Mapa $5^{22}$ ilustra o número médio de dias com geada/ano, que podem ocorrer no Paraná Central entre os meses de abril e setembro. Nos meses de junho a agosto, o quadrante da cafeicultura do Norte do Paraná está ameaçado por geadas (ver Cap. VII, 1). Para Londrina, p. ex., registra-se o valor 0,3, isto é, em média, 3 dias de geada por década. Como os terrenos de encostas com exposição em sentido norte estão protegidos do impacto de massas de ar frio, do sul, onde também se pode observar grande irregularidade na ocorrência de geadas noturnas, com o incentivo de solos férteis de terra roxa, a cafeicultura expande-se no Norte do Paraná até uma zona que no Mapa 5 se situa próximo da isolinha de 5 dias de geada/ano.

No Norte do Paraná devemos diferenciar dois tipos de geada:

a) A 'geada negra': que ocorre após o impacto de massas de ar frio, abrangendo grandes áreas. A água acumulada na galhada e na folhagem dos arbustos de café congela sob o efeito de ar seco e ventos fortes, e sua folhagem tinge-se de negro intenso, caindo do arbusto ${ }^{23}$.

b) A 'geada branca': tipo de geada ocorrida apenas em vales e depressões, como resultado de forte irradiação noturna e inversão térmica, que congelam o sereno acumulado na galhada e folhagem da vegetação.

Para a cafeicultura, as ameaças envolvendo o tipo 'a' são bem maiores, e todas as perdas ocorridas no Norte do Paraná e em São Paulo foram causadas por esse tipo de geada. Devido ao acúmulo estacionário de massas de ar frio, evita-se a cafeicultura em terrenos baixos e vales (Figuras 5 e 9). Já as plantações de café que se expandem sobre as cristas de encostas estão pouco ou nada expostas a geadas de irradiação.

Ainda não se pode responder satisfatoriamente se nas zonas-limite da cafeicultura as árvores de sombra poderiam servir de proteção contra geadas (SCHRÖDER, 1956b, p. 135). Enquanto o cultivo do café protegido por árvores de sombra em zonas com pronunciada estiagem sazonal não é possível em virtude da competição recíproca pela água, a cafeicultura concentrada na zona úmida do Norte do Paraná, sem a proteção de árvores de sombra, tem por objetivo maximizar as colheitas. Tendo como principal objetivo o predomínio do lucro, na fase pioneira deste modo de cultivo a rápida exaustão das plantas daí decorrente não foi detectada a tempo, ou foi simplesmente ignorada.

Na área estudada, as chuvas aumentam em sentido norte-sul de aprox. $1200 \mathrm{~mm}$ para 1650 $\mathrm{mm}$ arredondados (Mapa 6). Contudo, mais importante que o volume anual de precipitações é sua distribuição em volume e espaço ao longo do ano. Ocorre que o Norte do Paraná, assim, como São Paulo, caracteriza-se por períodos invernais secos e mais frios, como também por verões quentes e ricos em chuvas. Em oposição ao estado vizinho, ao norte, no Paraná, quanto mais meridional, tanto mais acentuado é um breve período secundário de chuvas, que ocorre antes da estiagem anual $^{24}$, de fundamental importância para o balanço hídrico das plantas (Figura 1) ${ }^{25}$.

22 Com base em CIBPU (1958, II) e nas indicações complementares de Maack (1968) para o Paraná.

23 Também chamada de 'geada preta' (ver Cap. VII, 1).

24 Schröder (1956b, p. 131) - ver também Figura 1.

25 Na Figura 1 puderam ser empregadas apenas 5 aferições de precipitação para a estação Cianorte (apud MAACK, 1968, p. 161), de modo que os valores médios apresentam ainda caráter descompensado, onde o período secundário de chuva, de abrilmaio, se manifesta estranhamente forte. 
Figura 1: Diagrama de clima e armazenamento de água em estações selecionadas do Norte do Paraná

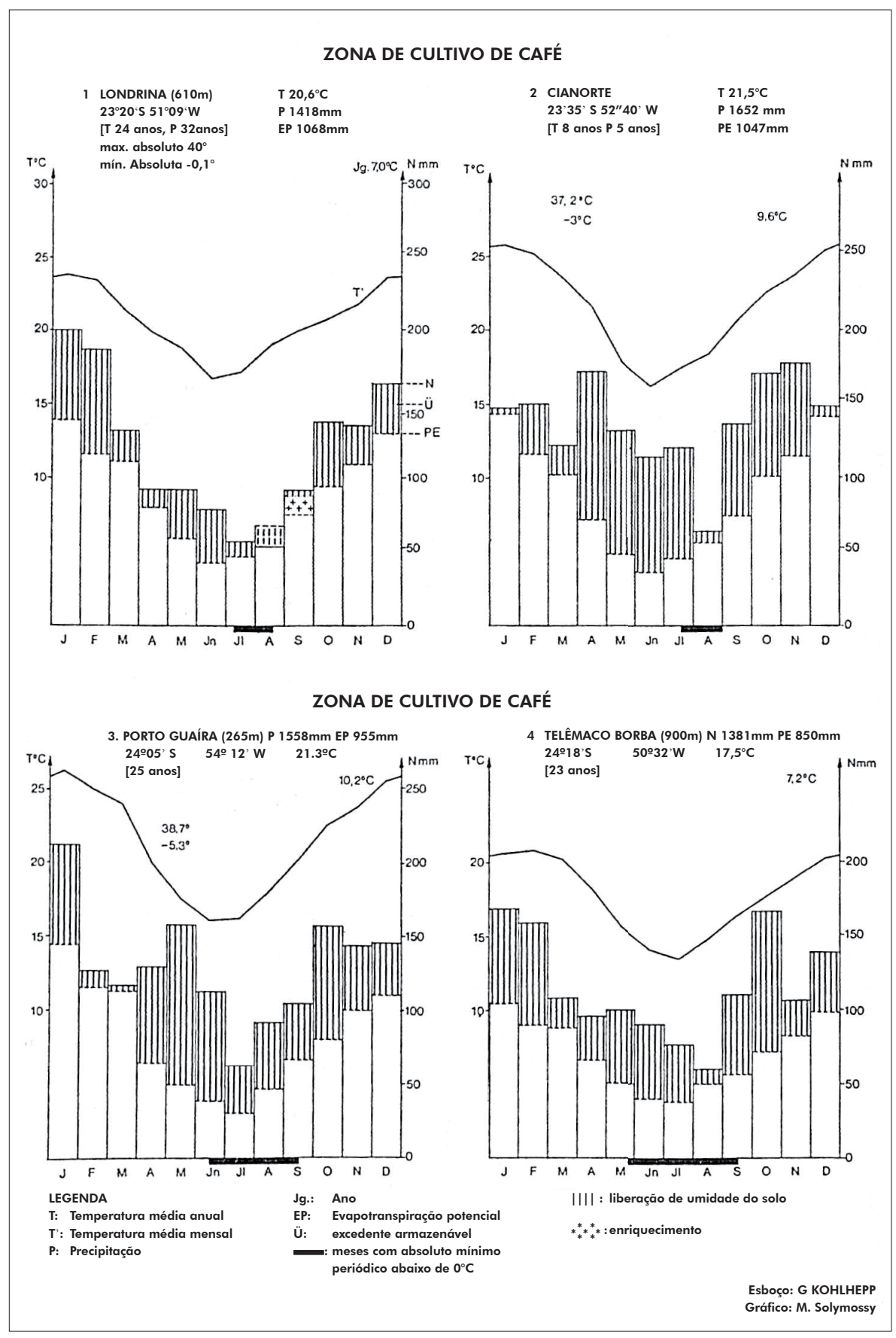


Em toda a extensão do degrau territorial do Planalto mesozoico, são alcançados níveis de precipitação anual de $1750 \mathrm{~mm}$, que soem expandir-se rapidamente em sentido nordeste ao território invernal, seco, de São Paulo (Mapa 6). Os meses mais quentes são julho e agosto, que, apesar da estiagem na região pesquisada, não deixam de apresentar precipitações levemente acima de $50 \mathrm{~mm}$. A distribuição das chuvas no Norte do Paraná por sua vez apresenta um andamento anual muito mais equilibrado do que no território de São Paulo, logo ao norte.

Este fenômeno tem efeito notável sobre o balanço hídrico das plantas da região, porque nesse balanço entre precipitação e evaporação aparecem meses completamente úmidos e também notáveis excedentes de umidade acumulada ${ }^{26}$. Após demorada observação, pode-se afirmar que na região cafeeira do Norte do Paraná, Londrina apresenta apenas o mês de agosto, subúmido, ao longo de 11 meses completamente úmidos ao ano (Figura 1). Segundo a classificação decimal hígrica estabelecida por Jätzold (1970), a Londrina corresponderia a zona $\mathrm{h}_{5,3}$ (isto é, úmida virtualmente o ano todo, compreendendo um breve interregno semiúmido) um clima agrário que apesar de sua alta umidade, e que é a característica das principais zonas cafeicultoras no Brasil da atualidade, parece ainda tolerável para o cultivo de Coffea arabica $^{27}$.

Segundo o ATLAS NACIONAL DO BRASIL (1966), o Norte do Paraná não apresenta um único mês genuinamente árido ao longo do ano, como ilustra o Mapa 6. Conforme as tabulações climatológicas para Porecatu ${ }^{28}$, na divisa com São Paulo, deve-se presumir, contudo, que uma faixa estreita, entre 30 e $40 \mathrm{~km}$, no norte extremo do Paraná, ao longo do Paranapanema, ainda apresente de 1 a 2 meses semiáridos, que não se manifestam nas grandes zonas cafeeiras, localizadas mais ao sul do Norte do Paraná.

Apesar de que um breve período de estiagem, como nas zonas de Araraquarense, Paulista e Mogiana em São Paulo, seja favorável à colheita e secagem do café, períodos de estiagem prolongada (abril/maio até setembro) foram muito frequentes em São Paulo na última década ${ }^{29}$, impactando negativamente as colheitas de café.

Em anos considerados normais, entretanto, no Norte do Paraná não há motivos para temer qualquer agravamento da falta de água. Entretanto, a evolução climática em anos mais recentes registra maior instabilidade, isto é: por um lado, há períodos de estiagem invernal, por outro, fortes chuvas invernais, cujas causas devem estar associadas ao excessivo desmatamento nas últimas décadas ${ }^{30}$.

Outro é o problema que afeta as regiões sem o referido déficit hígrico: a qualidade do sabor do café (tipos 'rio', 'riado'). Além disso, e baseado em experiências, nas regiões com déficit hígrico anual inferior a $70 \mathrm{~mm}$ se fez necessário o emprego de equipamento a ar quente para secagem, como é o caso no Norte do Paraná e de algumas zonas do sul do estado de São Paulo (CAMARGO, 1966, p. $12-13)^{31}$.

O início da colheita do café orienta-se pelas condições pluviométricas e, no Norte do Paraná, pelo menos em parte, somente pode ser iniciada no mês de junho.

Arbustos de café reagem muito suscetíveis à influência de ventos frios. No setor fronteiriço da cafeicultura do extremo meridiano do Norte do Paraná, que se encontra na zona de influência das frentes frias que avançam para o norte, o café evita as encostas expostas em direção ao sul.

26 O cálculo da evapotranspiração na Figura 1 foi realizado segundo o Método de Thornthwaite e Mather (1955), em base a documentos consultados na Secção de Climatologia Agrícola do Instituto Agronômico de Campinas (armazenamento de água $125 \mathrm{~mm})$.

27 O tipo $h_{3,4}$ (8-9 meses primordial e integralmente úmidos e 3-4 meses principalmente semiáridos) apresentado por Jätzold (1970, p. 66), baseado na descrição das condições climáticas de São Paulo por James (1932) , não se aplica para a cafeicultura brasileira em geral e, sim, apenas a um setor determinado de São Paulo. Desde 1932, o centro de gravidade da cafeicultura deslocou-se à grande distância da região central de São Paulo para o oeste e sudoeste, mais úmidos. Por sua vez, a experiência no Norte do Paraná demonstra que a Coffea arabica também se desenvolve de modo excelente sob condições do tipo climático $\mathrm{h}_{5,3}$ e até mesmo do $\mathrm{h}_{5,4}$ (ex.: Cianorte, Figura 1: 12 meses completamente úmidos - ver IBC $1970 \mathrm{~b}$ ).

28 Triagem própria do autor, de medições de temperatura e precipitações da fábrica de açúcar em Porecatu, completada por dados sobre o balanço hídrico de Porecatu, apud Holzmann (1967, p. 29).

29 Manifestação de períodos de estiagem extraordinariamente prolongados em São Paulo (Alta Araraquarense, em parte também Marília Mogiana): 1961, 1963, 1967, 1968, 1969.

30 Problema ao qual nos referimos pormenorizadamente no Cap. VIII, 4, ele foi objeto de pesquisa particularmente em variados trabalhos de Maack (entre outros 1953b, 1956, 1960, 1968). Sobre o Alto-Paraná, nos vizinhos Argentina e Paraguai, Wilhelmy (1950, p. 138-139) também apontou fortes desmatamentos como causa das alterações climáticas.

31 Para um déficit de $150 \mathrm{~mm}$ / ano, um cultivo longevo e economicamente rentável corre sérios riscos. 


\section{INVENTÁRIO VEGETACIONAL}

O caráter climático transitório nas zonas limítrofes do trópico no Brasil também se reflete na distribuição zonal da vegetação.

As florestas tropicais decíduas, que avançam Brasil adentro, até a latitude $24^{\circ}$, vinculando-se às florestas tropicais sempre verdes da Serra do Mar, confundem-se em sentido $\mathrm{N}$ e O com as florestas secas semidecíduas (Mapa 7).

No Paraná Central, além da depressão de alagamento, aprox. 25 a $30 \mathrm{~km}$ sobre território do Mato Grosso, a fronteira vegetacional corre entre as formações florestais e os campos cerrados do Brasil Central, apenas interrompidos por florestas de galeria, e que se caracterizam por, pelo menos, quatro meses áridos ao ano (PAFFEN, 1957, p. 221; LAUER, 1952; HUECK, 1966).

Aproximadamente à altura do rio Piquiri, no Paraná $\left(24^{\circ} \mathrm{S}\right)$, as florestas tropicais submergem nas florestas sempre verdes subtropicais dos grandes vales e zonas limítrofes, até altitudes de $500 \mathrm{~m}$. Exceção feita às calhas mais profundas de ar esfriado, esta altitude é o limite inferior da distribuição espacial da Araucaria angustifolia, que ocupa níveis elevados do Planalto Meridional.

Originalmente, os Nortes Novo e Novíssimo do Paraná eram cobertos por florestas tropicais pluviais. Apenas as zonas limítrofes meridionais do território aqui analisado eram povoadas respectivamente por floresta subtropical ou de araucárias (MAACK, 1950) 32.

A floresta tropical do Terceiro Planalto do Norte do Paraná caracterizava-se por solos vulcânicos residuais, ricos em palmáceas (Euterpe edulis), plantas epífitas, bromeliáceas e orquídeas. Exemplares notáveis, com mais de $30 \mathrm{~m}$ de altura, da figueira branca (Urostigma Ficus sp.) - a árvore mais alta da Floresta Pluvial Paranaense, com suas gigantescas raízes tabulares - e do pau d'alho (Gallesia gorarema), constituem a 'cobertura' do edifício florestal (MAACK, 1968, p. 214 ss.). Nele, a cabriúva (Myrocarpus fastigiatus), caviúna (Dalbergia niger), jacarandá (Machaerium sp.) e o pau marfim (Balfourodendron riedelianum) também eram espécies bem distribuídas. Contudo, a expansão da cafeicultura em grande medida devastou e extinguiu essas florestas pluviais. Várias espécies de peroba (Aspidosperma sp.), do cedro (Cedrela fissilis) e da canela (Ocotea pretiosa e Nectandra sp.) foram exploradas industrialmente.

Na região do Arenito Caiuá, a floresta tropical pluvial é menos pujante e suas árvores de menor tamanho. A virtual extinção da Euterpe edulis e a ocorrência de Arecastrum romanzoffianum torna-se visível na paisagem. Fazem falta a Gallesia gorarema, estimada por compradores de terras como sinal de solos férteis, e o Ficus. Ao longo do rio Paraná ocorre a palmeira macaúba (Acrocomia sclerocarpa). A floresta tropical sobre o Arenito Caiuá revela aspectos do cerradão, periodicamente seco (MAACK, 1949 e 1968; STELLFELD, 1949).

Ao sul da divisora de águas Ivaí-Piquiri, a floresta decidual é gradativamente substituída pela floresta subtropical pluvial, rica em ciateáceas, epífetas e cipós, na qual ainda persistem a Euterpe editlis e a Arecastrum romanzoffianum, mais resistente ao frio. Esta também se desenvolve na floresta tropical pluvial, em leitos de vales ameaçados por geadas, devido à acumulação de ar frio.

Na zona da divisora deáguas, a araucária avança notavelmente em sentido N, podendo ser observadas ainda algumas aglomerações a leste de Arapongas. Originalmente, as florestas de araucárias estavam amplamente distribuídas em toda área ao sul de Campo Mourão. Já na floresta mista de planalto, além da Araucaria angustifolia, com suas coroas planas à semelhança de guarda-chuvas, ocorrem ainda a imbuia (Phoebe porosa), Dicksonia sellowiana, Dalbergia brasiliensis, Machaerium sp., Balfourodendron riedelianum e a Ilex paraguariensis.

As araucárias, que em parte ocorrem sob forma de densas colônias, em grande medida caíram vitimadas pela depredação madeireira e só aparecem ainda nos pontos mais elevados e inacessíveis das bordas do Planalto.

Na zona a sudoeste de Campo Mourão, ocorrem grandes concentrações de erva-mate, que passaram a ser exploradas de forma planificada.

Os campos ocorrem em apenas duas 'ilhas', nos Nortes Novo e Novíssimo do Paraná, próximas de Campo Mourão $\left(100 \mathrm{~km}^{2}\right)$ e também entre Sabaudia e Astorga $\left(40 \mathrm{~km}^{2}\right)$ (Mapa 18). Os Campos Cerrados

32 Mapa fitogeográfico do Estado do Paraná 1:750 000. 
são relíquias de vegetação velho-quaternária (MAACK, 1968, p. 224), cujos representantes típicos são o Stryphnodendron adstringens (barbatimão) e a espécie palmácea Diplothemium campestre.

Originalmente, $47 \%$ da superfície total do estado do Paraná $\left(200.000 \mathrm{~km}^{2}\right)$ tinham cobertura de florestas pluviais tropicais e subtropicais, e $37 \%$ eram cobertos por florestas de araucárias ${ }^{33}$. As grandes migrações econômicas internas, a expansão de cultivos tropicais de longa duração (café), a partir de São Paulo, além da penetração, pelo sul, do sistema agrário de cultivos sobre alternação de solos, trazido pelos colonos de origem europeia, disseminaram as práticas das queimadas extensivas $^{34}$ (Fotos 2; 3); tais práticas foram agravadas pela exploração das florestas pela indústria e o comércio madeireiros. Essas tendências foram aguçadas com os grandes incêndios territoriais do ano de 1963, que devastaram principalmente o que restava das florestas de araucárias do Paraná Central ao Norte Novíssimo (LOWDEN, 1965; STERNBERG, 1968).

De acordo com Maack (1968, p. 199), em meados da década de 1960, aprox. 28\% da superfície do Paraná ainda possuíam cobertura de florestas pluviais, principalmente no Caiuá do noroeste do Estado (aprox. $10.500 \mathrm{~km}^{2}$ ). Neste ínterim, porém, a devastação florestal avançou, mesmo com o arrefecimento do boom da cafeicultura. Em seu lugar, surgiu a pecuária extensiva, que começou a cultivar pastos em gigantescas áreas florestais (Foto 16).

Com exceção do território da foz do Ivaí, as florestas tropicais pluviais que até há poucos anos avançavam vale adentro, desapareceram por completo. Atualmente (em 1970 [N.T.]), as poucas florestas subtropicais residuais da região do Piquiri, encontram-se desbastadas ao norte do rio, como também na zona de influência da migração interna gaúcha, ao sul do Piquiri, onde o desmatamento as reduziu a sobras insignificantes (Mapa 59).

Com minhas viagens realizadas ao Norte do Paraná em 1963, 1965, 1968 e 1970, pude constatar o processo de desmatamento irreversível que avançara ao longo daqueles anos. Se compararmos o estágio do desmatamento de 1963 com o de 1970, observamos uma alteração dramática na paisagem do Norte Novíssimo, a oeste de Umuarama: até 1963, nas florestas pluviais da região fora desmatada apenas uma trilha com 10 m de largura; a colonização apenas começara, com pequenas derrubadas localizadas. Em meados da década de 1960, porém, ocorreu o encontro das duas grandes frentes, nordeste e sul, de desmatamento por queimadas, que deixou para trás apenas restos de florestas carbonizadas. Com a devastação das florestas originárias e a alteração das condições do meio-ambiente, cinco a sete anos depois a fauna local estava quase que completamente aniquilada.

Enquanto a cafeicultura exigiu o desmatamento total nas atuais áreas de cultivo, instaladas em meio aos tocos das árvores, a criação de pastos para a pecuária na área do Caiuá apoiou-se exclusivamente nas queimadas, sem derrubadas prévias.

Hoje, em uma extensão de muitos quilômetros, o viajante se depara com ghost-forests, as florestasfantasmas, feitas de árvores solitárias, que remanescem como esqueletos carbonizados em meio aos pastos recém semeados.

Os amplos efeitos dessas interferências na paisagem natural já se traduzem, entre outros, em alterações do microclima, do balanço hidrológico, na forma de erosão, e deverão criar entraves para o desenvolvimento agrícola do Noroeste do Paraná.

\section{TIPOS DE SOLO E SEU VALOR DE EXPLORAÇÃO AGRÁRIA}

Enquanto a ocorrência de geadas determina a fronteira da zona agrícola tropical, delimitando o quadrante da cafeicultura paranaense em direção ao sul, a condição dos solos, conforme sua estratificação geológica na região pesquisada, permite uma classificação em sentido leste-oeste.

Grande parte do Norte Novo e um segmento do Norte Novíssimo erguem-se sobre solos profundamente depurados, com coloração de vermelho intenso, como aluviões de rochas eruptivas básicas (diábases, meláfiras, basaltos), também disseminados pelo oeste do Paraná. Esta assim chamada

33 Segundo cálculos de Maack (1968, p. 196 ss.).

34 Mapa 18 (Desmatamentos 1950) e Mapa 59 sobre o estágio da devastação florestal no final dos anos 1960. 
'terra' roxa pertence à categoria dos solos mais férteis do planeta e, por conseguinte, o solo ideal para a cafeicultura em ambiente livre de geadas. A terra roxa possui boa permeabilidade, como também boa capacidade de retenção da água, além de ser rica em minerais e matéria orgânica, apresentando índice baixo até neutro de reação, com $\mathrm{pH}$ de 6 a 7 .

Os latossolos de coloração vermelha até rubro-marrom apresentam diferenças graduais, conforme suas características físicas e químicas. Há diferenças estabelecidas, por exemplo, entre a chamada terra roxa legítima, que ocorre principalmente na região de Ribeirão Preto, São Paulo, e a terra roxa estruturada, do Paraná, que apresenta diferenças de coloração mais intensas entre os horizontes A e B, como também maior acumulação de materiais cerâmicos (SOUZA, 1965, p. 18) ${ }^{35}$.

Há ainda a 'terra roxa misturada', que em comparação com a terra roxa estruturada apresenta maior volume de material arenoso.

Em forma pura, a terra roxa ocorre principalmente em faixas superiores de solos, enquanto na área de contato com o arenito Caiuá, em solos de fundos de vale e de encostas, seja mais frequente o tipo misturado.

No Noroeste do Paraná, no Norte Novíssimo, as camadas vulcânicas encontram-se sobrepostas pelo Arenito Caiuá, que do Norte Novo também cobre parte das divisoras de água. Na zona principal de disseminação dos arenitos eólico-mesozoicos, predominam os solos arenosos de coloração vermelha clara a escura, que apresentam conteúdo nutricional inferior ao da terra roxa. Estes solos arenosos são extraordinariamente soltos, sua capacidade de retenção da água é baixa, têm reação ácida ( $\mathrm{pH} 4,3-5,8)$, e após breve período de exploração, perdem sua fertilidade. O desmatamento em grande escala no Norte do Paraná teve efeitos catastróficos exatamente nessa região, tais como a forte erosão de solos e a formação de 'sumidouros', que em parte forçaram até mesmo a mudança de núcleos de colonização. E isso não foi tudo, pois a erosão causada por ventos acarretou fortes danos por acumulação de areia em suspensão $0^{36}$.

Nas zonas de ocorrência da araucária e da erva-mate, os solos são significativamente mais ácidos.

Quando as camadas inferiores de lava são expostas nos vales dos arenitos, em parte sói ocorrer uma 'inversão do uso da terra': em oposição à habitual expansão da cafeicultura na região de encostas da terra roxa, as terras férteis de origem vulcânica da região do Caiuá estão situadas nos vales, enquanto as cumeeiras do relevo estão tomadas por solos arenosos de baixa fertilidade. Neste caso, e apesar do alto risco de geadas como resultado do congestionamento de massas de ar frio, o café é plantado nos vales.

A seguinte tabela de análises de solo em dois perfis, com cobertura florestal natural, ilustra as grandes diferenças na estrutura mecânica e química apresentada pelos dois principais tipos de solo do Norte do Paraná (Tabela 1).

Particularmente ilustrativa é a distribuição diferenciada de matéria orgânica (gradação de húmus), que no caso da terra roxa chega a quadruplicar o valor do solo arenoso da camada superior. No caso estudado, a discrepância entre os componentes minerais chega a oscilar entre 3 e 20 vezes a favor da terra roxa. O mais elevado índice nutricional da terra roxa no cotejo com os solos arenosos não se manifesta apenas através de colheitas maiores, mas principalmente em relação ao tempo de uso dos solos, que durante décadas não sofreram adubação e somente agora davam sinais de exaustão. Em comparação, em dez, no máximo doze anos, as colheitas extraídas dos solos arenosos despencam de modo tão vertiginoso, que a continuidade de exploração desses solos é virtualmente impossível sem adubação.

O quadro de comparação da distribuição regional dos cafezais, de acordo com o tipo de solo, no início da década de 1960, revelava as seguintes diferenças entre os Nortes Novo e Novíssimo do Paraná (IBC-OEA, 1964, p. 49-50).

35 Para abordagens gerais sobre o quesito qualidade dos solos de cultivo de café (VAGELER, 1939; COOLHAAS, FLUITER, KOENIG, 1960; FINCK, 1963).

36 Sobre os efeitos climáticos, pedológicos e econômicos da devastação florestal como resultado da colonização agrária no Norte do Paraná (ver Cap. VIII, 4). 
Do total de cafeeiros, havia as seguintes proporções de distribuição:

$\begin{array}{lcc} & \text { Norte Novo } & \text { Norte Novíssimo } \\ \text { em terra roxa estruturada } & 24 \% & 1 \% \\ \text { em terra roxa misturada } & 49 \% & 25 \% \\ \text { em solos arenosos } & 21 \% & 67 \% \\ \text { em outros solos } & 6 \% & 7 \%\end{array}$

O fato de que dois terços dos cafezais do Norte Novíssimo tenham sido plantados em solos arenosos, enquanto $73 \%$ dos pés de café do Norte Novo se encontram plantados em terra roxa, explica as diferentes tendências de desenvolvimento que ambas as regiões apresentam após a etapa pioneira da cafeicultura. Particularmente para a cafeicultura, a disseminação de solos arenosos no quadrante livre de geadas do Noroeste paranaense revela-se desvantajosa, dado que as zonas de terra roxa expandidas, que lhes fazem divisa ao sul, já se situam na região anualmente afetada por geadas, por isso consideradas impróprias para o cultivo de espécies tropicais.

Deste modo, em virtude de suas atribuições de clima e solo, o Norte Novo torna-se a região mais importante para a agricultura na região fronteiriça do trópico do Norte do Paraná. Na fase especulativa e conjuntural da expansão cafeeira, foi atribuída pouca importância às condições ambientais durante a ocupação dos solos e, ao que tudo indica, somente na década em curso é que parece ocorrer o que James (1932, p. 244) pôde observar em relação à cafeicultura de São Paulo: "Quanto mais intensiva se torna a economia, mais os padrões de distribuição se ajustam às qualidades subjacentes de ambiente físico"37.

37 No original: The more intensive the economy becomes, the more the patterns of distribution become adjusted to the underlying qualities of the physical milieu. 
Tabela 1: Análise de solos

\section{A. Terra roxa estruturada}

Perfil: Apucarana (Fazenda Ubatuba $750 \mathrm{~m}$ )

Vegetação: Floresta; Relevo: ligeiramente ondulado; Geologia: Diábases

Análise Mecânica (em \%)

\begin{tabular}{|c|c|c|c|c|c|}
\hline Horizonte & $\mathrm{cm}$ & Areia grossa & Areia fina & Lodo & Barro \\
\hline A1 & $0-25$ & 2,0 & 13,0 & 20,5 & 64,5 \\
\hline B1 & $25-53$ & 0,9 & 6,5 & 18,0 & 74,6 \\
\hline B21 & $53-103$ & 0,3 & 5,2 & 16,2 & 80,3 \\
\hline B22 & $103-163$ & 0,3 & 3,1 & 12,6 & 84,0 \\
\hline B3 & $163-203$ & 0,3 & 8,2 & 28,8 & 62,7 \\
\hline $\mathrm{C}$ & $203-253$ & 1,2 & 12,8 & 27,4 & 58,6 \\
\hline
\end{tabular}

Fonte: Perfil n. 1, (SOUZA, 1965, p. 28-31).

Análise química (em g/100 g)

\begin{tabular}{|c|c|c|c|c|c|c|c|c|}
\hline Horizonte & $\mathrm{pH}$ & Mat. Orgânico & C & $\mathrm{N}$ & $\mathrm{P}_{2} \mathrm{O}_{5}$ & $\mathrm{SiO}_{2}$ & $\mathrm{Al}_{2} \mathrm{O}_{3}$ & $\mathrm{Fe}_{2} \mathrm{O}_{3}$ \\
\hline A1 & 6,4 & 5,92 & 3,44 & 0,35 & 0,21 & 15,7 & 11,2 & 31,5 \\
\hline B1 & 5,6 & 1,93 & 1,12 & 0,13 & 0,15 & 19,1 & 17,2 & 34,3 \\
\hline B21 & 5,1 & 1,22 & 0,71 & 0,08 & 0,13 & 21,6 & 19,7 & 27,3 \\
\hline B22 & 5,3 & 0,77 & 0,45 & 0,06 & 0,12 & 20,3 & 15,0 & 23,2 \\
\hline B3 & 5,6 & 0,46 & 0,27 & 0,04 & 0,12 & 22,3 & 17,4 & 27,0 \\
\hline C & 5,0 & 0,45 & 0,26 & 0,04 & 0,19 & 22,3 & 14,5 & 23,5 \\
\hline
\end{tabular}

B. Latossolo arenoso, vermelho-escuro

Perfil: Nova Esperança (480 m) (6 km em direção a Alto Paraná)

Vegetação: Floresta; Relevo: ligeiramente ondulado; Geologia: Arenito Caiuá

Análise Mecânica (em \%)

\begin{tabular}{|c|c|c|c|c|c|}
\hline Horizonte & $\mathrm{cm}$ & Areia grossa & Areia fina & Lodo & Barro \\
\hline A1 & $0-18$ & 35,2 & 52,2 & 4,2 & 8,4 \\
\hline A3 & $18-39$ & 32,1 & 58,1 & 1,3 & 8,5 \\
\hline B1 & $39-67$ & 44,8 & 44,1 & 2,3 & 8,8 \\
\hline B21 & $67-162$ & 45,6 & 41,3 & 1,2 & 11,9 \\
\hline B22 & $162-212$ & 32,4 & 48,3 & 1,1 & 18,2 \\
\hline
\end{tabular}

Análise Química (em g/100 g)

\begin{tabular}{|c|c|c|c|c|c|c|c|c|}
\hline Horizonte & $\mathrm{pH}$ & Mat. Orgânico & C & $\mathrm{N}$ & $\mathrm{P}_{2} \mathrm{O}_{5}$ & $\mathrm{SiO}_{2}$ & $\mathrm{Al}_{2} \mathrm{O}_{3}$ & $\mathrm{Fe}_{2} \mathrm{O}_{3}$ \\
\hline A1 & 5,8 & 1,51 & 0,88 & 0,11 & 0,02 & 1,71 & 1,27 & 1,68 \\
\hline A3 & 5,5 & 0,27 & 0,16 & 0,02 & 0,01 & 1,87 & 1,15 & 2,32 \\
\hline B1 & 5,3 & 0,14 & 0,08 & 0,02 & 0,01 & 1,96 & 1,13 & 2,40 \\
\hline B21 & 5,2 & 0,10 & 0,06 & 0,01 & 0,01 & 2,71 & 1,84 & 2,48 \\
\hline B22 & 4,7 & 0,04 & 0,01 & 0,01 & 0,01 & 4,37 & 3,77 & 3,35 \\
\hline
\end{tabular}

Fonte: Perfil n. 6 (SOUZA, 1965, p. 43-45). 